\title{
Liver Insufficiency
}

National Cancer Institute

\section{Source}

National Cancer Institute. Liver Insufficiency. NCI Thesaurus. Code C141245.

The inability of the liver to perform its normal synthetic and metabolic functions. 